${ }^{1}$ Dr. Chishti Tanhar Bakth Choudhury MS (Surgery), MCPS (Gen. Surgery) Assistant Professor Dept. of surgery Northern International Medical College, Dhaka

${ }^{2}$ Prof. Dr. B H Nazma Yasmeen Professor and Head Dept. of Paediatrics Northern International Medical College, Dhaka

${ }^{3}$ Dr. Manir Hossain Khan MCPS, FCPS, MRCS (UK), (Gen. Surgery) Associate Professor, BSMMU

\section{${ }^{4}$ Dr. AHM Towhidul Alam Professor of Surgery Chairman Dept. of Surgery, BSMMU \\ ${ }^{5}$ Dr. Shirin Akhter Associate Professor Dept. of Gynae \& Obs Dhaka Central International Medical College, Dhaka}

Correspondence

Dr. Chishti Tanhar Bakth Choudhury MS (Surgery), MCPS (Gen.Surgery) Assistant Professor Dept. of surgery Northern International Medical College Hospital.

Email : chishtichoudhury@gmail.com

\title{
Superficial surgical site infections following stone and non-stone bile duct surgery. A comparative analysis
}

\author{
C T B Choudhury ${ }^{1}$, B H N Yasmeen ${ }^{2}$, M H Khan ${ }^{3}$, A H M T Alam ${ }^{4}$, S Akhter ${ }^{5}$
}

\begin{abstract}
Background : Superficial surgical site infection (SSSI) is a vital issue after biliary surgery. Surgical site infections remain a major cause of illness in the post-operative period.

Objectives : The purpose of the present study was to compare the number of wound infection and the causative organism of surgical site infection of patient of stone and non-stone bile duct surgery.

Methodology : This cross-sectional study was carried out in the Department of Surgery at Bangabandhu Sheikh Mujib Medical University (BSMMU), Dhaka from May 2017 to April 2018 for a period of 12 months. Patients presented with biliary disease of stone and non-stone variety were selected as study population. Patients were divided into 2 groups designated as group A and group B. Patients with the biliary stone disease were enrolled in group A and the biliary nonstone disease patients were in the group B. Patients were followed up in the postoperative period up to 2 weeks to find out the incidence of wound infection and its risk factors, causative agents, and some other variables. Certain variables were closely monitored to find the postoperative outcome as these variables were standard parameters in assessment of the outcome of the study.
\end{abstract}

Results : A total number of 50 patients were recruited for this study of which 25 patients were enrolled in group $A$ and the 25 patients were enrolled in group $B$. Mean age was $42.48 \pm 17.21$ years in group $A$ and $40.04 \pm 21.37$ years in group $B$. The difference was not statistically significant $(p=0.659)$. Males were predominant in both groups. Male female ratio was 1.77:1 and 1.08:1 in group $A$ and group $B$ respectively. Inflammatory evidence of gall bladder with pericholecystic collection was found in $5(20 \%)$ and $6(24 \%)$ patients in group A and group B. There was evidence of cholangitis in $8(32 \%)$ and $4(16 \%)$ patients in group $A$ and group $B$ respectively. Evidence of inflammation at the wound site, was found in $14(56 \%)$ patients in group A and $7(28 \%)$ patients in group B. There was statistically significant difference between these 2 groups in the incidence of superficial surgical site infection, ( $p$ value is 0.045 ). Regarding per operative collected bile, we found $E$. Coli in 4 cases in group $A$ and 3 cases in group $\mathrm{B}$ ( $p$ value is 0.408 ). Klebsiella spp. was found in 1 patient in group A. Wound swab $\mathrm{C} / \mathrm{S}$ identified $E$. Coli in 1 patient in group A. Staph aureus was found in 1 and 2 patients in group $A$ and group $B$ respectively ( $p$ value is nonsignificant).

Conclusion : In conclusion, there is a difference in the incidence of occurrence of surgical site infection and causative agents after stone and non-stone bile duct surgery. Stone disease has increased chance of wound infection than nonstone disease of bile ducts.

DOI: https://doi.org/10.3329/nimcj.v11i2.54061

Northern International Medical College Journal Vol. 11 No. 2 January 2020, Page $458-462$

\section{Introduction}

Surgical site infections (SSIs) are commonly associated with healthcare-associated infections (HAI). ${ }^{1}$ The United States Centers for Disease Control and Prevention has developed criteria that define SSI as an infection related to an operative procedure that occurs at or near the surgical incision within 30 days of the procedure or within 90 days if prosthetic material is implanted at surgery. ${ }^{1}$ SSIs are often localized to the incision site but can also extend into deeper adjacent structures. ${ }^{2}$

SSIs were the most common healthcareassociated infection, accounting for $31 \%$ of all HAIs among hospitalized patients. ${ }^{3}$ It remain as a substantial cause of morbidity, prolonged hospitalization, and death even though now a days much more scientific advances have been made in infection control practices. ${ }^{4}$ SSI is 
associated with a mortality rate of $3 \%$, and $75 \%$ of SSI associated deaths are directly attributable to the SSSI. ${ }^{5}$

In most post-operative SSIs, the causative pathogens originate from endogenous flora of the patient's skin, mucus membrane or hollow viscera. The most commonly isolated bacterial pathogens are S. aureus, E. coli, coagulase negative Staphylococci (CoNS), enterococci and Pseudomonas aeruginosa..$^{5}$ There is increase in incidence of SSIs attributed to antimicrobial resistant pathogenic bacteria like methicillin resistant Stap. aureus (MRSA) and vancomycin resistant Stap. aureus (VRSA).

Bile is generally sterile, in normal biliary tree. But during the diseases of the biliary tree bile may be infected; the reported incidence of bactobilia is variable. It is well established that bacteria are more common in bile if the patient is jaundiced particularly if biliary obstruction is due to stones or a benign bile duct stricture. Significant lower numbers of bacteria found in the bile of patients with malignant obstruction. The most frequently occurring diseases with infected bile include acute cholecystitis, choledocholithiasis, jaundice due to obstructive gallstones,

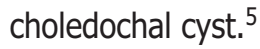

Infected bile is usually colonized by more than one organism. More complicated cases are also characterized by a greater number of bacteria; the most frequently occurring aerobes are Escherichia coli, Klebsiella species and Streptococcus faecalis, whereas Bacteroides fragilis and other Bacteroides species form the largest genus of anaerobic. ${ }^{3}$

Antimicrobial prophylaxis in surgery means the use of antibiotic to prevent infection. This does not involve prevention of secondary infections of wound or drain but concern only those infections caused by contamination during the operative procedure. Antimicrobial prophylaxis is not the alternative of inferior surgical practice or insufficient aseptic management.

Bacterial contamination of the surgical site is a prerequisite for SSIs. Following contamination, the risk of development of SSIs will depend on several factors, the most important ones being the dose and virulence of the pathogens, and host defense mechanism. Several preoperative, per operative, and postoperative predisposing factors have been studied and found that post-operative SSIs is associated with several risk factors. Diabetes mellitus, smoking and obesity are significantly associated with risk of SSIs. ${ }^{6}$ Similar findings was reported in addition to malnutrition, prolonged preoperative hospital stay and coexisting infections being risk factors. It has been reported that high nasal carriage of $\mathrm{S}$. aureus is the most important and significant independent risk factor for development of SSI with S. aureus. ${ }^{3}$

Some studies have reported a number of procedure related factors as contributory risk factors for the development of SSIs. ${ }^{6}$
In a study in Turkey found that abdominal incision, whole blood transfusion, early preoperative hair removal, inappropriate antimicrobial prophylaxis, as independent risk factor for SSIs. ${ }^{7}$ In another study in Northern Tanzania reported prolonged operation time, type of operation, type of incision, inappropriate anti microbial prophylaxis and increased time lapse between shaving and operation associated with increased risk of SSSI among patients who had undergone abdominal surgery. ${ }^{5}$

In this context the present study was undertaken to compare the incidence of occurrence of SSSI and the causative agents of surgical site infection between stone and non-stone bile duct surgery.

\section{Methodology}

This study was designed as a cross-sectional study and was carried out at the Department of Surgery in Bangabandhu Sheikh Mujib Medical University (BSMMU), Dhaka. The study was conducted from May 2017 to April 2018 for a period of 12 months.

Patients with biliary disease of stone and non-stone disease who were admitted for surgery were selected as study population. Patients were divided into two groups designated as group A and group B. Patients with the biliary stone disease were kept in group $A$ and the biliary non-stone disease patients were kept in the group $B$. The sample size of the present study was 50 patients, of which 25 patients were in group $A$ and the 25 cases were in group $B$.

The patients who were enrolled in this study were explained the whole procedure of the study. They were also informed that regular follow up would be done after operation. Written consent of the study population was taken. During admission of the patients all information like history, physical findings, relevant investigations results, and later the operative procedures, per operative findings and postoperative outcomes were recorded in the pre-designed data sheet.

In this study purposive sampling was done as per inclusions and exclusion criteria.

Inclusion criteria was stone in biliary tree, non-stone diseases are 1 . choledochal cyst 2 . Bile duct stricture 3 . periampullary CA 4. cholangiocarcinoma, 5.CA. head of pancreas.

Exclusion Criteria was -1 . Presence of features of acute cholangitis 2. Surgery in Gall stone disease.

The relevant socio-demographic data of all study patients were collected and recorded. Study variables were age, sex, clinical findings (Jaundice, history of cholangitis), previous medical illness (Diabetic, ischemic heart disease), use of antibiotics in last one month, history of ERCP, use of prophylactic antibiotic (inj. Cefuroxime), organism isolated in bile and organism 
isolated in infected wound.

Patients were followed up in the postoperative period up to 2 weeks even after discharge. Certain variables were closely monitored to see the incidence of wound infections as these variables were standard parameters in assessment of the outcome of the study. Per operative bile was collected and sent for culture. A sample of fluid, cells or tissue from the wound was collected from the wound infection during postoperative period and sent for culture to find the causative organism.

Data were collected in a preformed data collection sheet. Statistical analysis was performed by using Statistical Packages for Social Sciences (SPSS-22) (SPSS Inc, Chicago, IL, USA). Confidence limit- 95\% was taken. Parametric data was evaluated by ' $t$ ' test and non-parametric data was evaluated by Chi-square test as needed and significance will be defined as $p$ value $<0.05$. The summarized data was interpreted accordingly and was then presented in the form of tables.

\section{Results}

A total number of 50 patients were recruited for this study of which 25 patients were enrolled in group $A$ and 25 patients were enrolled in group B. According to age, all patients were divided in to 6 groups. Less than 10 years old no patients were found with biliary stone. Most of the patient $8(32 \%)$ with biliary stone were found in 31 - 40 years and more than 50 years old age group. In group B most of the $9(36 \%)$ biliary non stone disease were found in more than 50 years old people. Mean age of the study population in group A was $42.48 \pm 17.21$ and in group B $40.04 \pm 21.37$.(Table I)

Table I : Distribution of patients according to age $(n=50)$,

\begin{tabular}{|c|c|c|c|}
\hline Age (years) & $\begin{array}{l}\text { Group A (biliary stone) } \\
\text { No - \% } \\
\text { duct no - \% } \\
\text { dd } / \mathrm{s}\end{array}$ & $\begin{array}{c}\text { Group B (biliary non stone) } \\
\text { No - \% } \\
\text { (Stone in bile duct) } \\
\text { No - \% }\end{array}$ & $p$ value \\
\hline$\leq 10$ & $0(0.0)$ & $3(12.0)$ & 0.449 \\
\hline $11-20$ & $3(12.0)$ & $2(8.0)$ & \\
\hline $21-30$ & $3(12.0)$ & $4(16.0)$ & \\
\hline $31-40$ & $8(32.0)$ & $4(16.0)$ & \\
\hline $41-50$ & $3(12.0)$ & $3(12.0)$ & \\
\hline$>50$ & $8(32.0)$ & $9(36.0)$ & \\
\hline Total & $25(100.0)$ & $25(100.0)$ & \\
\hline Mean \pm SD & $42.48 \pm 17.21$ & $40.04 \pm 21.37$ & 0.659 \\
\hline Range (Min - Max) & $12-70$ & $2-70$ & \\
\hline
\end{tabular}

( $p$ value is not significant) $p$ value reached from unpaired t- test

In our study male were affected more than female both in biliary stone 16 disease (64\%) and biliary non stone disease 13 (52\%). (Table II)
Table II : Distribution of patients according to gender $(n=50)$

\begin{tabular}{|c|c|c|c|}
\hline \multirow[t]{4}{*}{ Gender } & \multicolumn{2}{|c|}{ Group } & \multirow[t]{4}{*}{$p$ value } \\
\hline & Group A & Group B & \\
\hline & (Stone in bile duct) & (Non stone bile duct) & \\
\hline & no- $\%$ & no- $\%$ & \\
\hline Male & $16(64.0)$ & $13(52.0)$ & 0.390 \\
\hline Female & $9(36.0)$ & $12(48.0)$ & \\
\hline Total & $25(100.0)$ & $25(100.0)$ & \\
\hline
\end{tabular}

$p$ value is not significant $p$ value reached from chi square test

Regarding clinical examination in this study, we found that jaundice was present in equal number (more or less) of patients in both the groups, in group A $20(80 \%)$ and in group B 21 (84\%). Previous medical illness (DM, HTN) was significantly higher in group B 9 (36\%). Positive history of cholangitis and ERCP were more in group A-14 (56\%) and12 (48\%) respectively than in group B. (Table III)

Table III : Clinical findings and history of patients in groups $(n=50)$

$\begin{array}{lccc}\text { Parameters } & \begin{array}{c}\text { Group A } \\ \text { (Stone bile duct) } \\ \text { no- \% }\end{array} & \begin{array}{c}\text { Group } \\ \text { (Non stone bile duct) } \\ \text { no- \% }\end{array} & \text { P value } \\ \text { Presence of jaundice } & 20(80.0) & 21(84.0) & 0.713 \\ \text { History of cholangitis } & 14(56.0) & 11(44.0) & 0.396 \\ \text { Previous medical illness } & 1(4.0) & 9(36.0) & 0.005 \\ \text { History of previous use of } & & & \\ \text { Antibiotics in last one month } & 19(76.0) & 14(56.0) & 0.136 \\ \text { History of ERCP } & 12(48.0) & 9(36.0) & 0.390 \\ \text { Prophylactic Antibiotic } & 25(100.0) & 25(100.0) & \end{array}$

(previous medical illness has significant $p$ value)

In this study per operatively we found that most of the patients had normal gall bladder in both groups $12(48 \%)$ and $15(60 \%)$. Evidence of inflammation in gall bladder was more in group $B, 6$ (24\%) but Evidence of cholangitis was more in group A-8 (32\%). (Table IV)

\begin{tabular}{|c|c|c|c|}
\hline \multirow{2}{*}{$\begin{array}{l}\text { Per operative } \\
\text { findings }\end{array}$} & \multicolumn{2}{|c|}{ Group } & \multirow[t]{2}{*}{$p$ value } \\
\hline & $\begin{array}{l}\text { Group A } \\
\text { tone in bile duct) } \\
\text { no- } \%\end{array}$ & $\begin{array}{c}\text { Group B } \\
\text { (Non stone bile duct) } \\
\text { no- } \%\end{array}$ & \\
\hline Gall bladder normal & $12(48.0)$ & $15(60.0)$ & \multirow[t]{4}{*}{0.415} \\
\hline $\begin{array}{l}\text { Evidence of inflammation } \\
\text { in gall bladder }\end{array}$ & $5(20.0)$ & $6(24.0)$ & \\
\hline Evidence of cholangitis & $8(32.0)$ & $4(16.0)$ & \\
\hline Total & $25(100.0)$ & $25(100.0)$ & \\
\hline
\end{tabular}

( $p$ value not significant) $p$ value reached from chi square test

In this study per operative examination of bile colour showed most of the patients $12(48 \%)$ and $14(56 \%)$ had purulent bile in group $A$ and group $B$ respectively. More patients had Normal colured bile $11(44 \%)$ in comparison with group B-9 (36\%). (Table V) 
Table V : Distribution of patients according to bile color in groups $(n=50)$

\begin{tabular}{lccc} 
Bile color & \multicolumn{2}{c}{ Group } & P value \\
& $\begin{array}{c}\text { Group A } \\
\text { (Stone in bile duct) }\end{array}$ & $\begin{array}{c}\text { Group B } \\
\text { (Non stone bile duct) }\end{array}$ & \\
& no- \% & no- \% & \\
Purulent & $12(48.0)$ & $14(56.0)$ & 0.838 \\
White & $2(8.0)$ & $2(8.0)$ & \\
Normal & $11(44.0)$ & $9(36.0)$ & \\
Total & $\mathbf{2 5 ( 1 0 0 . 0 )}$ & $\mathbf{2 5 ( 1 0 0 . 0 )}$
\end{tabular}

( $p$ value not significant) $p$ value reached from chi square test

On the 4th postoperative day, Superficial surgical site infections (SSSI) were found more in biliary stone diseases-14 (56\%) than in non-stone biliary diseases 7 (28\%). (Table-V)

Table VI : Distribution of patients according to wound site status at 4th postoperative day $(n=50)$,

\begin{tabular}{|c|c|c|c|}
\hline \multirow{2}{*}{$\begin{array}{l}\text { Wound site at } 4 \text { th } \\
\text { postoperative day }\end{array}$} & \multicolumn{2}{|c|}{ Group } & $p$ value \\
\hline & $\begin{array}{c}\text { Group A } \\
\text { (Stone bile duct) } \\
\text { no- } \%\end{array}$ & $\begin{array}{c}\text { Group B } \\
\text { (Non stone bile duct) } \\
\text { no- } \%\end{array}$ & \\
\hline Normal & $11(44.0)$ & $18(72.0)$ & 0.045 \\
\hline SSSI & $14(56.0)$ & $7(28.0)$ & \\
\hline Total & $25(100.0)$ & $25(100.0)$ & \\
\hline
\end{tabular}

( $p$ value significant) $p$ value reached from chi square test

E. Coli and Klebsiella spp were found more in bile of biliary stone diseases rather non stone disease (Table VII)

Table VII : Distribution of patients according to organisms isolated in bile $(n=50)$

$\begin{array}{lccc}\begin{array}{l}\text { Organism isolated } \\ \text { in bile }\end{array} & \begin{array}{c}\text { Group A } \\ \text { (Stone in bile duct) } \\ \text { no- \% }\end{array} & \begin{array}{c}\text { Group } \\ \text { (Non stone bile duct) }\end{array} & \\ \text { E. Coli } & 4(80.0) & 3(100.0) & 0.408 \\ \text { Klebsiella spp. } & 1(20.0) & 0(0.0) & \\ \text { Total } & \mathbf{5 ( 1 0 0 . 0 )} & \mathbf{3 ( 1 0 0 . 0 )} & \end{array}$

( $p$ value not significant) $p$ value reached from chi square test

E.Coli and Staph aureus were found in the infected wound swab $\mathrm{c} / \mathrm{s}$ of biliary stone diseases patient. (Table VIII)

Table VIII : Distribution of patients according to organisms isolated in infected wound $(n=50)$

$\begin{array}{lccc}\begin{array}{l}\text { Organism isolated } \\ \text { infected wound }\end{array} & \begin{array}{c}\text { Group A } \\ \text { (Stone in bile duct) }\end{array} & \begin{array}{c}\text { Group } \\ \text { (Non stone bile duct) }\end{array} & \\ & \text { no- \% } & \text { no- \% } & \\ \text { E. Coli } & 1(50.0) & 0(0.0) & 0.248 \\ \text { Staph aureus } & 1(50.0) & 2(100.0) & \\ \text { Total } & \mathbf{2 ( 1 0 0 . 0 )} & \mathbf{2 ( 1 0 0 . 0 )}\end{array}$

( $p$ value not significant) $p$ value reached from chi square test

\section{Discussion}

This study was designed to find out the incidence of occurrence and the causative agents of superficial surgical site infections after biliary stone disease and biliary non stone disease surgery.

In this study Mean age was $42.48 \pm 17.21$ years in group $A$ and $40.04 \pm 21.37$ years in group B. which was not statistically significant. Results similar to the present study, one prospective observational study was identified which showed- age as an independent risk factor for SSI. ${ }^{8}$ Similarly patients aged over 40 had a statistically significant increased risk of developing SSI compared with those under 40 years. ${ }^{9}$ Age was found to be a statistically significant risk factor for SSI incidence in our study as well as both of these studies. 8,9

In our study, males were predominant in both groups. Male female ratio was 1.77:1 and 1.08:1 in group A and group B respectively. There was no statistically significant difference between these two groups.

In this study, most of patients in both groups had jaundice (group A: $80 \%$; group B: $84 \%$ ). and history cholangitis (group A: $56 \%$; group B: $44 \%$ ). but there was no statistically significant difference between these two groups. History of Previous medical illness (eg. DM, IHD) was significantly higher in group B $(36.0 \%)$ than group A (4.0\%) and was statistically significant. Studies report a two- to three-fold increase in risk of developing an SSI in patients with diabetes. This may be related to altered cellular immune function. One large prospective study of procedures on mostly clean wounds in children and adults reported that malnutrition increased the incidence of SSI from $1.8 \%$ to $16.6 \% .^{10}$ Similar result was found in the study of Kaya et al. they also found that malnutrition, prolonged preoperative hospital stays, and coexisting infections were act as risk factors. ${ }^{6}$

Per operative finding in groups were recorded. Evidence of Inflammation in gal. History of cholangitis was higher in group A $(56.0 \%)$, history of previous use of Antibiotics within the last one month was higher in group A (76.0\%), and history of ERCP also higher in group A (48.0\%) but the differences were not statistically significant in all situations than that of group $B$.

In our study inflammation of gall bladder was found in $5(20.0 \%)$ and $6(24.0 \%)$ patients in group A and group B respectively. There was evidence of cholangitis in $8(32.0 \%)$ and $4(16.0 \%)$ patients in group A and group B respectively. There was no statistically significant difference between these two groups. In this study we found that bile color was purulent in $12(48.0 \%)$ cases and white in $2(8.0 \%)$ cases in group $A$ and in group B it was purulent in $14(56.0 \%)$ cases and white in $2(8.0 \%)$ cases. There was no statistically significant difference between these two groups.

Finally, in this study when we observed the wound site on 4th 
postoperative day, SSSI was found in $14(56.0 \%)$ and $7(28.0 \%)$ patients in group A and group B respectively. There was statistically significant difference was found between these two groups. Even though same prophylactic Antibiotic was given to all the patients of both groups.

A prospective study with the patients undergoing biliary tract operations showed that despite all patients received the same prophylactic antibiotic, bile colonization remains the major factor associated with postoperative sepsis. ${ }^{11}$ In another study it was found that antibiotic prophylaxis reduced high rate of infection in selected high-risk patients (age over 70, obstructive jaundice, common duct stones without jaundice and emergent acute cholecystitis). ${ }^{12}$

Previous studies revealed that after biliary tract surgery postoperative wound infection rates vary from $2 \%$ after uncomplicated cholecystectomy to $20 \%$ in series including many jaundiced patients. These infections were arising from organisms growing in the diseased biliary tract. But the infection rate was only $1 \%$, when the bile was sterile. ${ }^{12}$

Regarding organisms isolated in bile, $E$. coli was found in $4(80 \%)$ and $3(100 \%)$ patients in group A and group B respectively. Klebsiella spp. was found in 1 patient in group $A$. There was no statistically significant difference between these two groups. In this study, organisms isolated in the infected wound was E. coli in 1 patient in group A. Staph aureus was found in $1(50 \%)$ and $2(100 \%)$ patients in group A and group B respectively. There was no statistically significant difference between these two groups. In our study Esch. coli, Klebsiella spp were found in bile cultures. Also in South East Asia these are the most common organisms found in bile cultures which causes recurrent cholangitis. ${ }^{13}$

\section{Conclusion}

There is a difference in the occurrence of surgical site infections after stone and non-stone bile duct surgery. Stone disease has increased chances of superficial surgical site infections than nonstone disease.

\section{References}

1. CDC. April 2013 CDC/NHSN Protocol Corrections, Clarification, and additions ttp://www.cdc.gov/nhsn/PDFs/pscManual/9pscSSIcurrent.pdf (Accessed on July 10, 2013)
2. Mangram, A.J., Horan, T.C., Pearson, M.L., Silver, L.C., Jarvis, W.R. 1999 'Gui deline for Prevention of Surgical Site Infection, 1999. Centers for Disease Control and Prevention (CDC) Hospital Infection Control Practices Advisory Committee', Am J Infect Control, 27, 97-132.

3. Magill, S.S., Hellinger, W., Cohen, J., Kay, R., Bailey, C., Boland, B, et al. 2012 'Prevalence of healthcare-associated infections in acute care hospitals in Jacksonville, Florida', Infection Control \& Hospital Epidemiology, 33(03), 283291

4. CDC National and state Healthcare-associated infections progress report, published March 2014, available at http://www.cdc.gov/HAI/ pdfs/progressreport/hai- progressreport.pdf

5. Awad, S.S. 2012 'Adherence to surgical care improvement project measures and post-operative surgical site infections', Surgical infections, 13(4), 234237

6. Kaya, E., Yetim, I., Dervisoglu, A., Sunbul, M., Bek, Y. 2006 'Risk factors for and effect of a one-year surveillance program on surgical site infection at a university hospital in Turkey', Surg Infect (Larchmt), 7, pp. 519-26.

7. Eriksen, H.M., Chugulu, S., Kondo, S., Lingaas, E. 2003 'Surgical siteinfections at Kilimanjaro Christian Scott, J.D., Forrest, A., Feurstein, S., Fitzpatrick, P., Schentag, J.J. 2001 'Factors associated with postoperative infection', Infection Control and Hospital Epidemiology, 22, 347-51Medical Centre', J Hosp Infect, $55,14-20$

8. Scott, J.D., Forrest, A., Feurstein, S., Fitzpatrick, P., Schentag, J.J. 2001 'Factors associated with postoperative infection', Infection Control and Hospital Epidemiology, 22, 347-51

9. Ridgeway, S., Wilson, J., Charlet, A., Kafatos, G., Pearson, A., Coello, R. 2005 'Infection of the surgical site after arthroplasty of the hip', Journal of Bone and Joint Surgery - British, 87 . 844-50

10. Abboud, C.S., Wey, S.B., Baltar, V.T. 2004 'risk factors for mediasti Anderson, D.J. 2011 'Surgical Site Infections', infect dis clin N Am, 25, 135-153sts, 27 sussex place, regent's Park, London NW1 4RG; October 2008

11. G R Wells, E W Taylor, G Lindsay, L Morton. Relationship between bile colonization, high risk factors, postoperative sepsis in patients undergoing biliary tract operation while receiving a prophylactic antibiotic. West of Scotland Surgical Infection Study Group. Br J Surg.1989 Apr;76(4):374-7. PMID: 2497926 doi: 10.1002/bjs.1800760419.

12.D W Elliott. Biliary tract surgery; South Med J. 1977 Oct;70 Suppl 1:31-5. PMID: 910186 doi: 10.1097/00007611-197710001-00008.

13.Eimear Brannigan, PengWong, David Leaper. Abdominal and other surgical infections. In Drs. Finch, Greenwood, Whitley, and Norrby, editors. Antibiotic and Chemotherapy. 9th ed.Elsevier, 2010: 483-501. https://doi.org/ 10.1016/B978-0-7020-4064-1.00039-7 